\title{
Spatial synchrony of population changes in rocky shore communities in Shetland
}

\author{
Michael T. Burrows ${ }^{1, *}$, Jon J. Moore ${ }^{2}$, Ben James ${ }^{2, * *}$ \\ ${ }^{1}$ Scottish Association for Marine Science, Dunstaffnage Marine Laboratory, Oban, Argyll PA37 1QA, Scotland, UK \\ ${ }^{2}$ CORDAH Limited, Pentlands Science Park, Penicuick, Near Edinburgh EH26 0PH, Scotland, UK
}

\begin{abstract}
Rocky shore monitoring around the Sullom Voe Oil Terminal in Shetland has produced a 20 yr dataset of population fluctuations for 40-plus species at 15 to 20 sites separated by distances up to $30 \mathrm{~km}$. Synchrony in population changes was quantified by correlation among series of abundance categorised on quantitative scales. Two periods were analysed separately, pre- and post-1992, following changes in methods and extent of monitoring. Positive average correlations among sites were found for 10 out of 16 species pre-1992 and for 23 out of 26 post-1992, statistically significant for 4 and 8 species for the 2 periods, respectively. The intertidal barnacle Semibalanus balanoides showed most synchrony among sites for both periods, while dogwhelks Nucella lapillus and macroalgae (Fucus vesiculosus, F. serratus, Mastocarpus stellatus) had very low average correlations among sites. Littorina saxatilis was the only other species with significant positive correlation among sites in both periods. Corallinaceae, Verrucaria maura and V. mucosa, and Littorina neglecta were less synchronised pre-1992 than post-1992, while L. obtusata showed less synchrony post-1992. Differences in reproductive biology and ecology failed to explain patterns of synchrony among species. Species with planktonic larvae were no more likely to be synchronised than those without. There was a tendency for species living higher on the shore to be more synchronised post-1992, but species predominant on wave-exposed shores were no more synchronous than sheltered-shore species. The more synchronised species in this study need to be monitored at relatively few sites to detect change, whereas more sites may be needed for species in which change occurs on a local scale. Population synchrony also suggested usefulness of species as indicators of large-scale change: the barnacle $S$. balanoides is the best indicator among species in the study area.
\end{abstract}

KEY WORDS: Population synchrony $\cdot$ Rocky shore communities $\cdot$ Monitoring methods

Resale or republication not permitted without written consent of the publisher

\section{INTRODUCTION}

While explicit studies of population synchrony in marine species have been rare (but see Higgins et al. 1997), rocky shore ecologists have long been aware of the spatial scale of temporal changes in intertidal communities. Spatial scales of change have emerged from long-term monitoring of intertidal biota at yearly and

\footnotetext{
*E-mail: mtb@wpo.nerc.ac.uk

${ }^{* *}$ Present address: Scottish Natural Heritage, 2 Anderson Place, Edinburgh EH6 5NP, Scotland, UK
}

less frequent intervals. Although examples of such studies are well known and the causes of patterns well understood, no particular scales of change have emerged that are consistent among taxa. For example, changes in barnacle populations in SW England, from abundant Semibalanus balanoides in the 1930s to predominantly Chthamalus stellatus in the 1950s, were found to extend over a broad area of western Britain and Ireland (Southward \& Crisp 1954, 1956). Subsequent changes were closely associated with changes in temperature (Southward 1967, 1980, 1991, Southward et al. 1995). The 'Torrey Canyon' oil spill and cleanup caused another broad-scale, community-level change 
(Southward \& Southward 1978, Hawkins \& Southward 1992) in the same region. Both these examples suggest large-scale synchrony of community change. On Australian shores, in contrast, changes in algae on the low and mid-shore appear idiosyncratic (Chapman \& Underwood 1998, Underwood \& Chapman 1998), with no 2 sites showing similar changes. In South Africa, however, some similarities in long-term trends have been seen among sites separated by up to $240 \mathrm{~km}$ (Dye 1998a). In the latter study, and some others (Kendall et al. 1985, Svane 1984), the degree of similarity in temporal change among sites was determined by correlation among time series. The use of correlation to determine spatial synchrony in population changes among spatial networks of sites has been the focus of many recent studies (see Koenig 1999 for review). Such studies address the nature of the pattern of response over a geographical scale rather than the environmental factors producing change, and may cast new light on studies of long-term change in marine communities. Not least, the method offers an objective index of synchrony that may be compared among different taxa and spatial scales.

There are thought to be 2 major causes of spatial synchrony in populations (Ranta et al. 1995, 1997, Koenig 1999). The first is when a spatially autocorrelated density-independent factor ('disturbance') synchronises fluctuations that are controlled by a common density-dependent structure (the 'Moran effect'; Moran 1953, Ranta et al. 1997). The second is dispersal

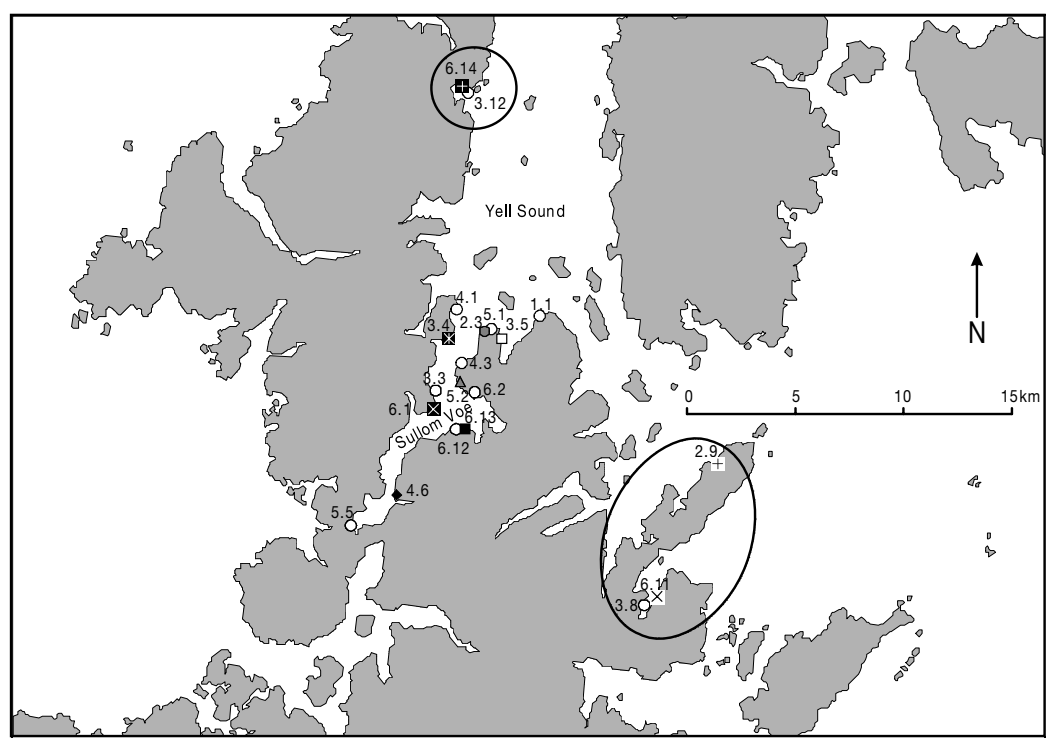

Fig. 1. Location of sites around Sullom Voe, Shetland. Sites are distinguished by a decimal code, whereby the integer portion denotes the wave exposure determined on the biologically defined exposure scale (Ballantine 1961). Outlying sites $(6.11,3.4,2.9,6.14,3.12)$ were monitored from 1993 onwards. Symbols used as in Fig. 2 between neighbouring areas. Dispersal makes synchrony decline with distance in a way that depends on the scale of dispersal (Bjørnstad \& Bolker 2000). Another possible cause of synchrony may be roaming predators that switch between areas with high densities of prey (Koenig 1999).

Notwithstanding the causes, the degree of synchrony among spatially separate populations has obvious consequences for environmental monitoring. Where population changes occur simultaneously over a broad spatial scale, just 1 or 2 monitoring sites will indicate the status of the entire area. Where synchrony is limited to areas within sites or to closely grouped sites, a broad spatial network of monitoring sites will be needed to determine the status of species over a wide area.

Regular monitoring of rocky shore populations in and around Sullom Voe, Shetland, has provided the opportunity to access long time series of population changes for a spatial network of monitoring sites. After early broad-scale surveys starting in 1976 (Hiscock 1981), the present set of 15 core sites has been surveyed every year since 1981 (Fig. 1). Another 5 sites were added in 1993, which were $>10 \mathrm{~km}$ from the terminal, to aid discrimination of changes in the vicinity of the potential impact sites from those occurring over a broader geographical scale. The survey methodology involved assigning abundance of the conspicuous species to logarithmic or semi-logarithmic categories. Precision was thereby sacrificed to allow typically 30 to 50 species to be assessed at 5 shore levels at each site, yet producing data that is still amenable to numerical analysis. The resulting data set is an unparalleled collection of spatially referenced time series of abundance for a broad range of contrasting species.

In the present study we analyse the Sullom Voe rocky shore survey data for synchrony of population changes in a wide range of contrasting species. Established information on biology and dynamics of populations of the species involved can be used with the synchrony measured here to deduce the most likely causes. Consequences for monitoring rocky shore communities are discussed.

\section{MATERIALS AND METHODS}

Field surveys. Sites were originally chosen to detect change in rocky shore communities around the oil terminal at Sullom Voe (Fig. 1). After a survey of many sites over a broad geographical 
Table 1. Numerical equivalents for categorical estimates of abundance following Hiscock (1981) definitions (categories: A, absent; R, rare; O, occasional; F, frequent; C, common; A, abundant; S, super-abundant; Ex, extremely abundant). Values chosen are midpoints between scale limits, with 'absent' on the scale replaced by the lower limit of the 'rare' scale

\begin{tabular}{|c|c|c|c|c|c|c|c|c|c|c|}
\hline \multirow[t]{2}{*}{ Species } & \multirow[t]{2}{*}{ Scale } & \multirow[t]{2}{*}{ Unit } & \multicolumn{5}{|c|}{ - Abundance class } & \multirow[b]{2}{*}{ A } & \multirow[b]{2}{*}{$\mathrm{S}$} & \multirow[b]{2}{*}{ Ex } \\
\hline & & & A & $\mathrm{R}$ & $\mathrm{O}$ & $\mathrm{F}$ & $\mathrm{C}$ & & & \\
\hline \multicolumn{11}{|l|}{ Live barnacles, } \\
\hline Littorina neritoides, L. neglecta & 1 & $0.01 \mathrm{~m}^{2}$ & 0.001 & 0.005 & 0.5 & 5 & 50 & 200 & 400 & 600 \\
\hline Balanus perforatus & 2 & $0.01 \mathrm{~m}^{2}$ & 0.001 & 0.005 & 0.05 & 0.5 & 5 & 55 & 200 & 350 \\
\hline \multicolumn{11}{|l|}{ Patella adults, $L$. littorea, } \\
\hline L. mariae/obtusata, Nucella lapillus $(<3 \mathrm{~mm})$ & 1) 3 & $0.1 \mathrm{~m}^{2}$ & 0.01 & 0.05 & 0.25 & 0.75 & 2.5 & 7.5 & 15 & 30 \\
\hline L. 'saxatilis', Patella $(<10 \mathrm{~mm})$ & 4 & $0.1 \mathrm{~m}^{2}$ & 0.01 & 0.05 & 0.5 & 2.5 & 7.5 & 15 & 35 & 60 \\
\hline Nucella lapillus (>3 mm), Gibbula sp. & 5 & $0.1 \mathrm{~m}^{2}$ & 0.1 & 0.25 & 0.5 & 2.5 & 7.5 & 25 & 75 & 130 \\
\hline Mytilus edulis & 6 & $\%$ & 0.01 & 0.1 & 1 & 2.5 & 12 & 35 & 65 & 90 \\
\hline Pomatoceros sp. & 7 & $0.01 \mathrm{~m}^{2}$ & 0.001 & 0.005 & 0.05 & 0.5 & 25 & 60 & & \\
\hline Spirorbinidae & 8 & $0.1 \mathrm{~m}^{2}$ & 0.001 & 0.005 & 0.05 & 0.5 & 50 & 150 & & \\
\hline Sponges, hydroids, bryozoans & 9 & $\%$ & 0.01 & 0.1 & 1 & 2.5 & 12 & 25 & & \\
\hline Lichens, lithothamnia & 10 & $\%$ & 0.01 & 0.1 & 0.5 & 2.5 & 10 & 35 & 65 & 90 \\
\hline Algae & 11 & $\%$ & 0.01 & 0.2 & 1 & 2.5 & 17 & 45 & 75 & 95 \\
\hline
\end{tabular}

area (Hiscock 1981), a core set of 15 sites around the terminal was chosen for annual monitoring in August of each year. This core set of sites was visited from 1981 until 1992. Reconsideration of the power of the sampling scheme to detect and discriminate natural from anthropogenic change (at the terminal) led to the addition of more distant sites to the core set (Fig. 1). It was felt that the concentration of effort $<10 \mathrm{~km}$ distant from the potential source of effects was not the best use of resources, given that no sites could be considered as control sites in a before-after/control-impact design (Underwood \& Peterson 1988). The full set of 15 core sites and 5 reference sites was visited yearly from 1993 to 2000 .

Each site survey consisted of a fixed transect relocated in the same position each year (Moore et al. 1995). Stations were set up along the transect line at $20 \mathrm{~cm}$ vertical intervals. Abundances of the major animal and plant species were estimated at 5 of these stations at each site: lower shore (LS), lower middle shore (LMS), middle shore (MS), upper middle shore (UMS) and upper shore (US), corresponding approximately to mean low water spring (MLWS), mean low water neap (MLWN), mean tidal low (MTL), mean high water neap (MHWN) and mean high water spring (MHWS). Before 1992, abundances were also recorded at every $20 \mathrm{~cm}$ interval on the transect line.

Abundance was scored on a 7-point scale of abundance appropriate to each taxon (Hiscock 1981, modified from Crisp \& Southward 1958; Table 1). These scales provide rapid estimates of population density based on limited quadrat counts. Category intervals are similar on logarithmic scales, and are sufficiently well spaced to be not easily misjudged. Use of these scales by different workers during different phases of the study may have contributed to some variability in abundance estimates. Such effects have not been accounted for in subsequent analyses.

Data analysis. As a result of the added sites and the reduced number of stations per site from 1993, the time series was divided into 2 periods for analysis: 1981 to 1992 and 1993 to 2000. All abundance scores were replaced by the midpoint value on the appropriate scale (Table 1). Thus a score of 'common' for barnacles, corresponding to 10 to 99 per $0.01 \mathrm{~m}^{2}$, was converted to a value of 50 per $0.01 \mathrm{~m}^{2}$. These values were converted to $\log$ base 10 . When abundance was zero for a station at a site in a particular year, this was interpreted either as absence if the species were found at other stations at the site, or as a missing value if the species were not recorded at all at the site on that visit. Absence was valued as a population density an order of magnitude less than the minimum defined in the appropriate scale. Average log-transformed abundance was calculated over all 5 shore levels at each site to provide a single time series for each species at the site.

Selection of species for analysis of spatial synchrony depended on 2 criteria: that the species were sufficiently ubiquitous (present at $>75 \%$ of sites) and were recorded in at least half the years surveyed. Twentysix species met these criteria for the period 1993 to 2000, while 16 qualified for the period 1981 to 1992.

Synchrony was quantified by correlation among all the time series for each species. The effects of distance on synchrony were determined by linear regression of correlation coefficients on the distance between each site. Because the same sets of data were used many times in calculations, the correlation coefficients could not be considered to be independent of each other. This non-independence of data invalidated standard 
statistical tests of significance. Therefore, as in similar studies (Swanson \& Johnson 1999, Paradis et al. 2000), for each species the statistical significance of the average correlation among sites and the linear regression coefficient of correlation on distance were determined using bootstrap methods (Efron \& Gong 1983). Selecting 20 sites from the original set with replacement produced a bootstrap sample of the original 20 sites. Correlation coefficients between sites in the bootstrap sample were used to calculate an average correlation and a linear regression of correlation versus distance. This process was repeated 500 times for each species and time period. The mean and standard error of the resulting 500 values of correlation and regression coefficients were used in $t$-tests to determine whether mean values were significantly different from zero.

\section{RESULTS}

\section{Patterns of synchrony}

For the period from 1981 to 1992,10 of the 16 species had positive average coefficients of correlation among sites (Table 2) with 4 significant values. For 1993 to 2000, 23 out of 26 species had positive average correlation coefficients, of which 8 were significantly different from zero.

Four taxa showed much greater synchrony among sites in the 1990s than in the 1980s: Corallinaceae, Verrucaria maura and V. mucosa, and Littorina neglecta, while Littorina obtusata showed less synchrony in the 1990s than in the 1980s. The remaining taxa had consistent levels of synchrony in both decades. Semibalanus balanoides, the dominant barnacle species in the area, showed the strongest synchrony of all species in both the 1980s and 1990s, with averages significantly different from zero in both periods. The degree of synchrony is evident from plots of time series from a subset of the sites. Abundance of $S$. balanoides declined to and increased from a minimum in 1992 at all sites (Fig. 2a). Littorina saxatilis was the only other taxon with significant positive averages in both periods (Fig. 2b), with maxima at a number of sites evident in the late 1980s and again in the mid-1990s. Adult limpets (Patella sp.) were intermediate in the strength of synchrony, with little evidence for clear changes across all sites, albeit with a slight increase from the

Table 2. Average correlations $\left(\mathrm{r}_{\mathrm{boot}}\right)$ between time series of average abundance at monitoring sites around Sullom Voe. Estimated averages and standard errors $\left(\mathrm{SEr}_{\text {boot }}\right)$ were determined through bootstrap resampling of the set of sites $\left(N_{\mathrm{S}}\right)$ where the species occurred to select from the set of correlations between sites $\left(N_{\mathrm{C}}\right)$. Values significantly different from zero are shown by an asterisk $(\mathrm{p}<0.05)$. Values are sorted in descending order for the 1993 to 2000 period (scale, abundance scale, see Table 1)

\begin{tabular}{|c|c|c|c|c|c|c|c|c|c|}
\hline \multirow[t]{2}{*}{ Species } & \multirow[t]{2}{*}{ Scale } & \multicolumn{4}{|c|}{$-1981-1992-$} & \multirow[b]{2}{*}{$N_{\mathrm{C}}$} & \multicolumn{2}{|c|}{ - 1993-2000 } & \multirow[b]{2}{*}{$\mathrm{SEr}_{\text {boot }}$} \\
\hline & & $N_{\mathrm{C}}$ & $N_{\mathrm{S}}$ & $\mathrm{r}_{\text {boot }}$ & $\mathrm{SEr}_{\text {boot }}$ & & $N_{\mathrm{S}}$ & $r_{\text {boot }}$ & \\
\hline Semibalanus balanoides & 1 & 210 & 15 & 0.2664 & $0.0489^{*}$ & 400 & 20 & 0.3511 & $0.0973^{*}$ \\
\hline Corallinaceae & 10 & 110 & 12 & 0.0299 & 0.0962 & 324 & 19 & 0.2951 & $0.0824^{*}$ \\
\hline Hildenbrandia spp. & 10 & & & & & 400 & 20 & 0.2872 & $0.0895^{*}$ \\
\hline Porphyra spp. & 11 & & & & & 252 & 18 & 0.2728 & $0.1115^{*}$ \\
\hline Fucus spp. (sporelings) & 11 & & & & & 361 & 20 & 0.2582 & $0.0801^{*}$ \\
\hline Verrucaria maura & 10 & 178 & 15 & -0.0381 & 0.0552 & 400 & 20 & 0.2339 & $0.0693^{*}$ \\
\hline Littorina neglecta & 1 & 142 & 15 & -0.0213 & 0.0855 & 287 & 19 & 0.1761 & 0.1150 \\
\hline Littorina saxatilis & 4 & 210 & 15 & 0.3274 & $0.0596^{*}$ & 400 & 20 & 0.1717 & $0.0751^{*}$ \\
\hline Bowerbankia sp. & 9 & & & & & 359 & 19 & 0.1652 & $0.0706^{*}$ \\
\hline Cladophora spp. & 11 & & & & & 308 & 18 & 0.1391 & 0.0787 \\
\hline Verrucaria mucosa & 10 & 182 & 15 & -0.0505 & 0.0513 & 400 & 20 & 0.1318 & 0.0865 \\
\hline Corallina sp. & 11 & & & & & 196 & 15 & 0.1211 & 0.0919 \\
\hline Pelvetia canaliculata & 11 & & & & & 167 & 18 & 0.1150 & 0.1366 \\
\hline Patella spp. (<10 mm) & 4 & 100 & 13 & 0.1725 & 0.1081 & 349 & 20 & 0.1115 & 0.0894 \\
\hline Patella spp. (all) & 3 & 210 & 15 & 0.1067 & $0.0419^{*}$ & 400 & 20 & 0.1018 & 0.0547 \\
\hline Ceramium spp. & 11 & & & & & 144 & 15 & 0.0550 & 0.0991 \\
\hline Mytilus edulis & 6 & 180 & 15 & 0.1336 & 0.0717 & 386 & 20 & 0.0424 & 0.0610 \\
\hline Littorina obtusata & 3 & 156 & 13 & 0.2649 & $0.0819^{*}$ & 337 & 20 & 0.0294 & 0.0900 \\
\hline Enteromorpha spp. & 11 & & & & & 370 & 20 & 0.0257 & 0.0875 \\
\hline Fucus vesiculosus & 11 & 154 & 14 & 0.0675 & 0.0700 & 287 & 18 & 0.0172 & 0.0730 \\
\hline Halichondria panicea & 9 & & & & & 169 & 17 & 0.0145 & 0.1032 \\
\hline Nucella lapillus & 5 & 176 & 15 & 0.0246 & 0.0564 & 169 & 15 & 0.0116 & 0.1063 \\
\hline Spirorbidae & 8 & 52 & 11 & -0.0571 & 0.1286 & 279 & 19 & 0.0107 & 0.0763 \\
\hline Littorina littorea & 3 & 90 & 13 & 0.1072 & 0.1063 & 221 & 16 & -0.0076 & 0.0900 \\
\hline Fucus serratus & 11 & 152 & 15 & -0.0445 & 0.0684 & 314 & 19 & -0.0153 & 0.0683 \\
\hline Mastocarpus stellatus & 11 & 130 & 15 & -0.0295 & 0.0629 & 320 & 20 & -0.0328 & 0.0622 \\
\hline
\end{tabular}


1980s to 1990s (Fig. 2c). The pattern of changes in abundance of L. obtusata (Fig. 2d) showed similar maxima and minima to that of $L$. saxatilis.

Several species showed low or no apparent overall correlation among sites. Dogwhelks, Nucella lapillus, and the algae Fucus vesiculosus, F. serratus and Mastocarpus stellatus had very low average correlation coefficients. As expected, for these species no changes in abundance over time were discernible that were common to all sites (Fig. 2e,f).

Synchrony in population changes was expected to decline with the distance separating the sites compared. A declining trend in synchrony with distance was indeed evident in the most synchronised species, Semibalanus balanoides (Fig. 3). However, none of the bootstrap estimates of regression slope was signifi- cantly different from zero, out of the 16 and 26 calculated for 1981 to 1992 and 1993 to 2000 periods, respectively. Neither was there a tendency for regression slopes to be negative. Ten regression slopes out of 16 for 1981 to 1992 and 10 of 26 for 1993 to 2000 were negative, frequencies not significantly different from an expectation of 50:50.

\section{Associations of synchrony with species characteristics}

The association of species synchrony with species abundance, aspects of vertical distribution, whether animal or plant species, and approximations of the length of dispersal phase effects was measured by
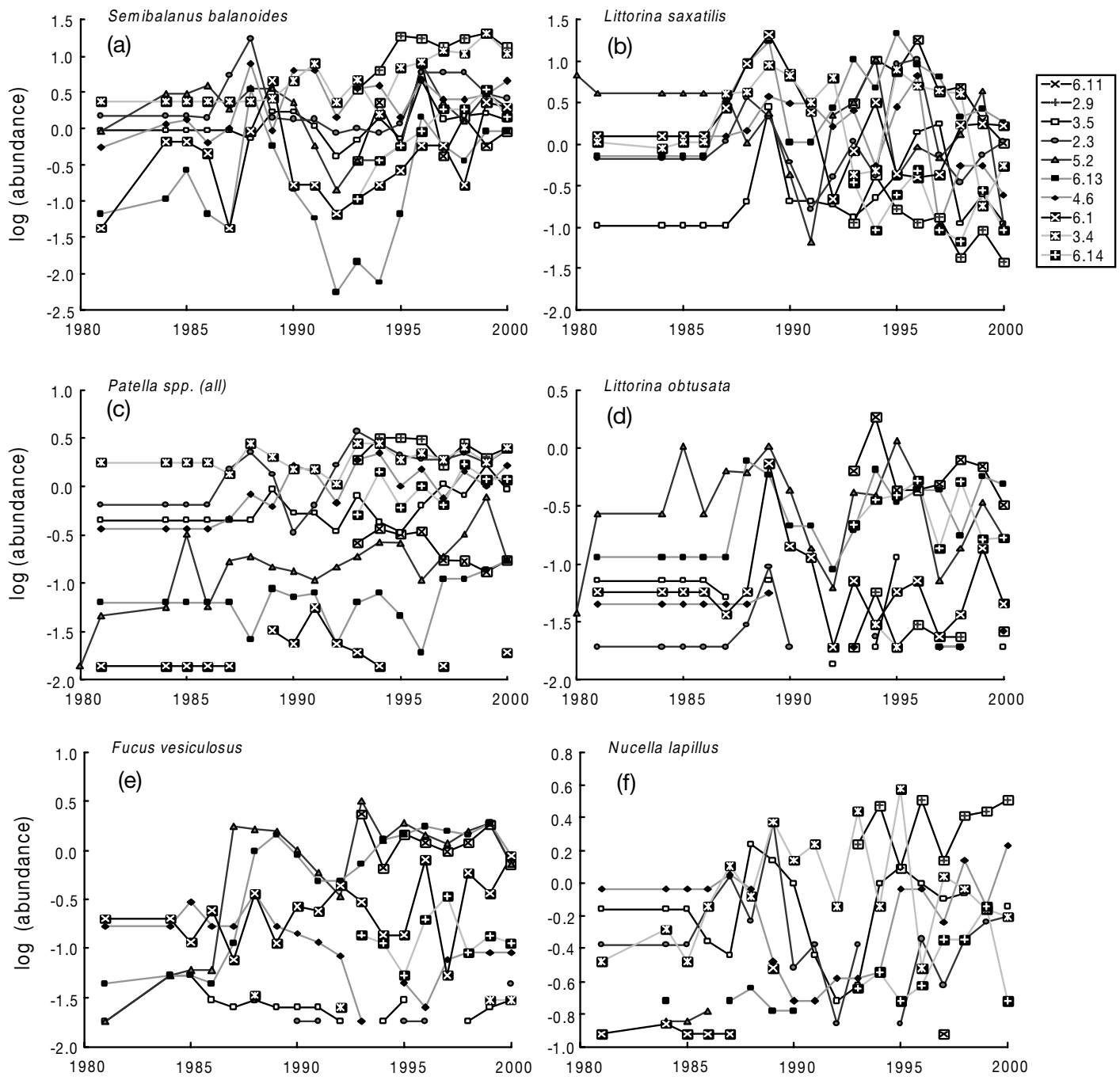

Fig. 2. Time series of average abundance (log scale) at 10 out of the 20 monitored sites. Only alternate sites are shown for clarity. Symbols and decimal site codes as in Fig. 1. Plots are arranged in descending order of degree of synchrony for 1993 to 2000 : (a) Semibalanus balanoides, $\mathrm{r}_{\text {boot }}=0.35$; (b) Littorina saxatilis, 0.17; (c) Patella sp. adults, 0.11; (d) Littorina obtusata, 0.03; (e) Fucus vesiculosus, 0.02; (f) Nucella lapillus, 0.01 
simple correlation (Tables $3 \& 4$ ). Taking the average correlation across the range of sites as the measure of synchrony, it can be seen that species present at more sites in more years were more likely to have larger average correlation. The duration of the larval phase had no significant consistent effect on synchrony for the whole set of species. Some species with planktonic larvae showed very little synchrony (Littorina littorea), while others (Semibalanus balanoides) were strongly synchronised. Animals were more synchronised than plants during the 1980s, but this effect was not seen in the second time period.

In the second time period, species living higher on the shore, with a greater vertical range and with an upper limit near the top of the shore, tended to be syn-
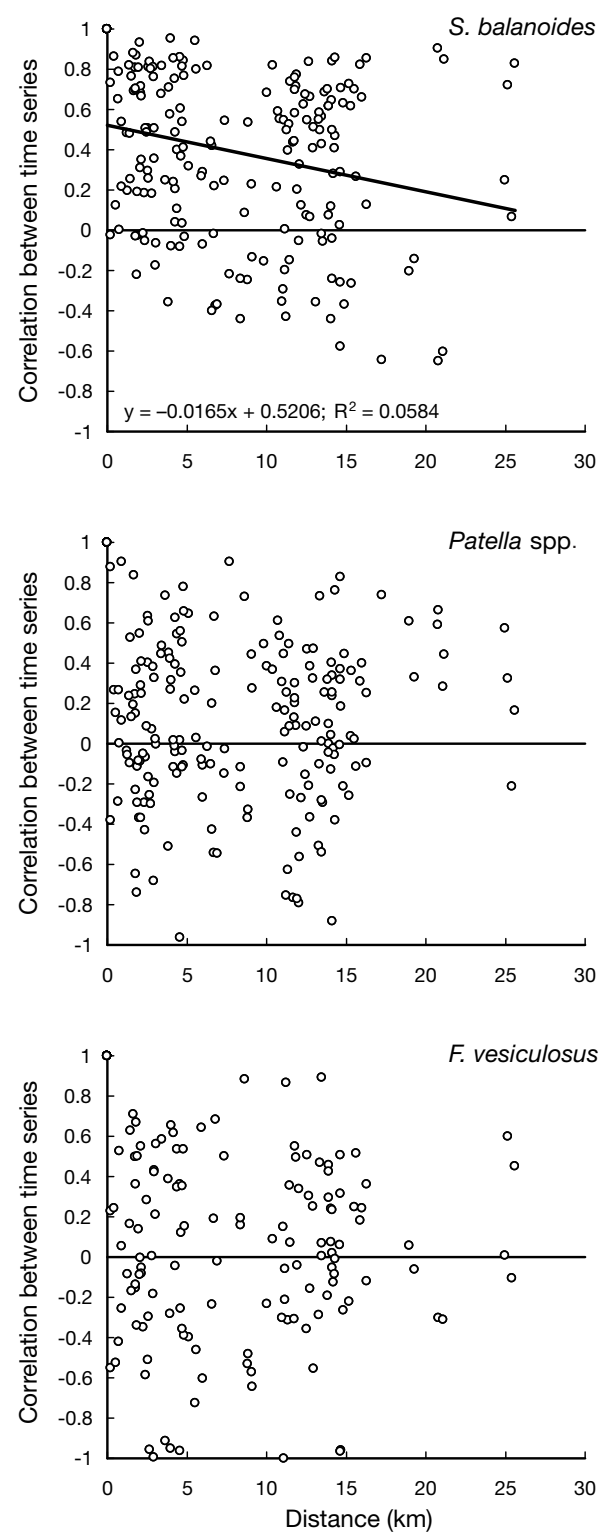

chronised across the sites. Thus species living lower on the shore, in narrower zones, were less synchronous. The height of the lower limit of the species had little effect. Finally, certain species in the set were more abundant at wave-exposed sites while others were more typical of sheltered sites. To quantify this tendency, a principal components analysis was done on the average abundance for species in Table 2 at each site over the $20 \mathrm{yr}$ of data (1981 to 2000). The first principal component explained $36.5 \%$ of the total variance and was strongly correlated with the exposure rating of the site as originally defined on the Ballantine (1961) scale (Kendall's tau $b=-0.785, \mathrm{n}=20, \mathrm{p}<0.0001$ ). Thus the factor loading for each species for the first principal component was a good measure of affinity for
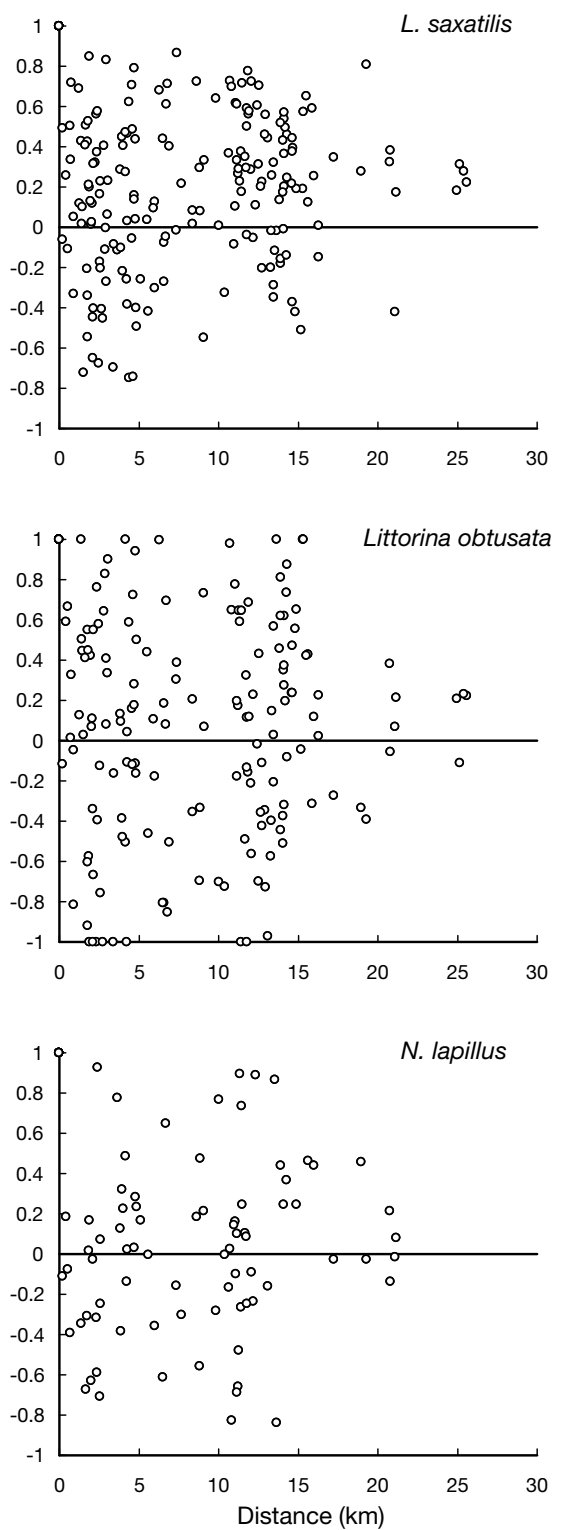

Fig. 3. Population synchrony as the correlation between time series versus distance between pairs of sites, for the period 1993 to 2000 
Table 3. Species characteristics. As in Table 2, species are arranged in descending order of synchrony for the period 1993 to 2000. (D: duration of dispersal phase; K: kingdom [A: animal; P: plants/lichens]; P10 and P90, 10th and 90th percentiles; PC1, factor loading from PCA ranging from -1 for sheltered-shore species to +1 for exposed-shore species)

\begin{tabular}{|c|c|c|c|c|c|c|c|c|}
\hline Species & Dispersal mode & $\mathrm{D}(\mathrm{d})$ & $\mathrm{K}$ & \multicolumn{2}{|c|}{$\begin{array}{l}\text { Mean shoreLevel range } \\
\text { level }\end{array}$} & $\begin{array}{c}\text { P10 } \\
\text { upper }\end{array}$ & $\begin{array}{c}\text { P90 } \\
\text { lower }\end{array}$ & $\mathrm{PC} 1$ \\
\hline Semibalanus balanoides & Planktonic & 28 & A & 1.0 & 3.3 & MTL & MLWS & 0.65 \\
\hline Corallinaceae & Zoospore & 2 & $\mathrm{P}$ & 0.6 & 0.6 & MLWN & MLWS & 0.36 \\
\hline Hildenbrandia spp. & Zoospore & 2 & $\mathrm{P}$ & 1.1 & 0.7 & MHWN & MLWS & -0.32 \\
\hline Porphyra spp. & Zoospore & 2 & $\mathrm{P}$ & 0.9 & 0.7 & MHWN & MLWS & 0.54 \\
\hline Fucus spp. (sporelings) & Zoospore & 2 & $\mathrm{P}$ & 1.1 & 1.0 & MHWN & MLWS & -0.72 \\
\hline Verrucaria maura & Spore & 2 & $\mathrm{P}$ & 2.1 & 0.9 & MHWS & MHWN & 0.58 \\
\hline Littorina neglecta & Live-bearing & 0 & A & 1.2 & 2.0 & MTL & MLWN & 0.82 \\
\hline Littorina saxatilis & Live-bearing & 0 & A & 1.5 & 1.9 & MHWS & MLWN & -0.56 \\
\hline Bowerbankia sp. & Lecithotrophic & 2 & $\mathrm{~A}$ & 1.0 & 0.1 & MHWN & MLWN & -0.36 \\
\hline Cladophora spp. & Zoospore & 2 & $\mathrm{P}$ & 0.7 & 0.3 & MTL & MLWS & 0.63 \\
\hline Verrucaria mucosa & Spore & 2 & $\mathrm{P}$ & 1.5 & 1.0 & MHWS & MLWN & -0.01 \\
\hline Corallina sp. & Zoospore & 2 & $\mathrm{P}$ & 0.5 & 0.4 & MLWN & MLWS & 0.68 \\
\hline Pelvetia canaliculata & Zoospore & 2 & $\mathrm{P}$ & 1.9 & 0.5 & MHWS & MHWN & -0.18 \\
\hline Patella spp. $(<10 \mathrm{~mm})$ & Planktotrophic & 7 & A & 0.6 & 0.5 & MLWN & MLWS & 0.80 \\
\hline Patella spp. (all) & Planktotrophic & 7 & A & 0.9 & 0.9 & MTL & MLWS & 0.87 \\
\hline Ceramium spp. & Zoospore & 2 & $\mathrm{P}$ & 0.6 & 0.3 & MLWN & MLWS & 0.77 \\
\hline Mytilus edulis & Planktonic & 21 & $\mathrm{~A}$ & 0.6 & 0.5 & MLWN & MLWS & 0.71 \\
\hline Littorina obtusata & Encapsulated & 0 & $\mathrm{~A}$ & 0.9 & 0.7 & MTL & MLWS & -0.82 \\
\hline Enteromorpha spp. & Zoospore & 2 & $\mathrm{P}$ & 0.9 & 0.8 & MHWN & MLWS & 0.03 \\
\hline Fucus vesiculosus & Zoospore & 2 & $\mathrm{P}$ & 1.0 & 1.2 & MTL & MLWS & -0.85 \\
\hline Halichondria panicea & Lecithotrophic & 2 & A & 0.5 & 0.2 & MLWS & MLWS & 0.24 \\
\hline Nucella lapillus & Encapsulated & 0 & $\mathrm{~A}$ & 0.8 & 1.0 & MTL & MLWS & 0.81 \\
\hline Spirorbidae & Planktonic & 14 & $\mathrm{~A}$ & 0.5 & 0.7 & MLWN & MLWS & -0.39 \\
\hline Littorina littorea & Planktonic & 28 & A & 0.8 & 0.5 & MTL & MLWS & -0.80 \\
\hline Fucus serratus & Zoospore & 2 & $\mathrm{P}$ & 0.5 & 0.5 & MLWN & MLWS & -0.53 \\
\hline Mastocarpus stellatus & Zoospore & 2 & $\mathrm{P}$ & 0.5 & 0.3 & MLWS & MLWS & 0.22 \\
\hline
\end{tabular}

wave exposure or shelter (Table 3). Species more common on wave-exposed shores were not more synchronous than those more common on sheltered shores.

\section{DISCUSSION}

In this study changes in abundance of most species were positively correlated among sites, with $25 \%$ (4 of
16) and $31 \%$ (8 of 26) significantly greater than zero. Given that many previous studies have identified large-scale changes in abundance and distribution of barnacles (see 'Introduction'), it was perhaps not surprising that Semibalanus balanoides was the most synchronised of all species examined (1981 to 1992: 0.27; 1993 to 2000: 0.35). This species is one of the few intertidal species for which population synchrony has previously been quantified. Peak settlement counts of $S$.

Table 4. Associations of species synchrony with species characteristics measured by correlation. Pearson correlation coefficients; significant values: ${ }^{*} \mathrm{p}<0.05$

\begin{tabular}{|c|c|c|c|c|c|}
\hline Abundance & $1981-1992$ & $1993-2000$ & Vertical distribution & $1981-1992$ & $1993-2000$ \\
\hline Number of species & 16 & 26 & Number of species & 16 & 26 \\
\hline Number of observations & 0.360 & $0.455^{*}$ & Average shore height & 0.030 & $0.394^{*}$ \\
\hline Number of sites & 0.034 & 0.310 & $\begin{array}{l}\text { Vertical range } \\
\text { (SD height) }\end{array}$ & 0.405 & $0.470^{*}$ \\
\hline Number of coefficients & 0.384 & $0.400^{*}$ & $\begin{array}{l}\text { Upper limit } \\
\text { (90th percentile height) }\end{array}$ & 0.171 & $0.450^{*}$ \\
\hline Duration of planktonic phase (square root d) & 0.130 & 0.003 & $\begin{array}{l}\text { Lower limit } \\
\text { (10th percentile height) }\end{array}$ & -0.218 & 0.214 \\
\hline Kingdom (animal $=1$, plant/fungus $=0$ ) & $0.571^{*}$ & -0.173 & $\begin{array}{l}\text { Wave exposure } \\
\text { (PC1) }\end{array}$ & -0.127 & 0.196 \\
\hline
\end{tabular}


balanoides from 1975 to 1981 in North Yorkshire (Kendall et al. 1982) were very strongly correlated among sites ( $\mathrm{r}=0.6$ to 0.95 ) along a $60 \mathrm{~km}$ stretch of linear coast, while over the same period along a complex coastline in NW Scotland a wider range of correlation was seen (-0.16 to 0.98). Reduced synchrony along a complex coastline may be due to differences in orientation and coastal configuration among sites, resulting in a greater range of environmental conditions among sites separated by similar distances (Kendall et al. 1982) and of the potential supply of wind-driven dispersal stages (Hawkins \& Hartnoll 1982). Large-scale synchrony of changes in barnacle populations has also been seen in Tetraclita serrata in South Africa (Dye 1998a).

By contrast with Semibalanus balanoides, the dogwhelk Nucella lapillus showed very little synchrony. The species has very limited dispersal, producing egg capsules and having a high degree of microgeographic genetic variability (Day 1990, Kirby et al. 1997). Populations in the vicinity of the oil terminal at Sullom Voe have advanced tributyltin-induced imposex from the antifouling paints used on large ships (Davies \& Bailey 1991, Harding et al. 1997). Decline, extinction and subsequent partial recovery of dogwhelk populations in this area can be seen in the time series (Fig. 2f). The localised effect reduced the correlation among the populations in the whole area. Possible consequences for other species resulting from the changes in dogwhelk populations (Moore et al. 1995) were not investigated.

From the above examples it is tempting to draw generalities as to the influence of the characteristics of particular species on degree of synchrony. Species with broad-scale dispersal of long-lived larvae would seem predisposed to show synchronised changes across a broad range of sites, while those with limited dispersal such as macroalgae (Sousa 1984, Reed et al. 1988) might be more likely to be synchronised over shorter distances. Analysis of association of degree of synchrony with species characteristics showed no effect of the mode and degree of dispersal. Littorina littorea also has an extended pelagic larval phase, yet showed no significant synchrony among the sites in either period. The general conclusion that widely dispersed species are more synchronised is therefore not supported by the present set of species and sites.

The nature and causes of synchrony may be specific to particular spatial scales. Synchrony on very small scales (1 to $100 \mathrm{~m}$ ) may be due to the dynamics of community patches, driven by patchy disturbance and recovery (Sousa 1984), of species interactions (Burrows \& Hawkins 1998, Johnson et al. 1998, Johnson 2000). Where spatial interaction effects ensure that adjacent patches cycle out of phase with each other, this may account for positive trends of spatial autocorrelation with distance at small scales (Heino et al. 1997). Smallscale variation in abundance due to patchiness may influence yearly site values when fixed study sites are used, as in this study.

At larger spatial scales (typically beyond $10 \mathrm{~s}$ of $\mathrm{km}$ ) spatially autocorrelated disturbance (the Moran effect) and dispersal are the dominant causes of synchrony. In terrestrial systems spatial synchrony of population fluctuations over 100s of $\mathrm{km}$ is common: in the UK, butterflies (Pollard 1991) and birds (Paradis et al. 2000) have been shown to be dominated by widespread factors. Separating the Moran effect from that of dispersal-induced synchrony requires a more thorough understanding of the density dependence of the populations involved (Swanson \& Johnson 1999). Both effects may act. Density-dependent cycles in red grouse and rock ptarmigan populations are synchronised by weather (the Moran effect), but dispersal plays some part in entraining changes in adjacent areas (Watson et al. 2000).

For those marine species with planktonic larvae, such as sessile invertebrates (Roughgarden et al. 1988, Underwood \& Fairweather 1989) or teleost fishes (e.g. plaice, Ziljstra \& Witte 1985), population fluctuations are thought to be driven by variation in larval supply. While this may imply that dispersal should be an important influence on synchrony, it may be that vulnerability of early life stages to environmental conditions varying on large scales is the dominant cause. Evidence for the latter is to be found in the often strong association of synchronous changes with environmental conditions. Plaice recruitment time series around the UK over the last 20 to 40 yr are strongly correlated (Fox et al. 2000), with a common signal correlated with sea temperature. Barnacles in SW England (Southward et al. 1995) also follow temperature, while widescale synchrony in California is driven by interannual variation in coastal upwelling affecting offshore advection of larvae (Roughgarden et al. 1988).

For some species there may be an influence of wider geographical distributions. Those species operating near limits may rely on sporadic successful recruitment events (Lewis et al. 1982). Successive failure of recruitment may ultimately lead to local extinction and thus a change in distribution. This phenomenon may produce synchrony through a Moran effect operating on dispersal stages, but not through dispersal itself. Semibalanus balanoides is also strongly temporally synchronised, with the synchronous release of larvae occurring over a wide area (Kendall et al. 1985), possibly to coincide with the presence of food species in the plankton (Barnes 1956).

At the level of whole rocky shore communities, longterm studies produce inconsistent conclusions as to the 
spatial scale of temporal change. Large-scale, longterm changes may dominate variation in abundance and community composition, and are thought to be associated with oceanographic processes (Shanks 1983, Underwood et al. 1983, Caffey 1985, Gaines et al. 1985, Dayton et al. 1999). Where these changes have been analysed statistically, major shifts in community structure have been found to be due to changes in a subset of species. On South African shores, changes in community composition common to distant sites were mostly due to changes in the barnacle species (Dye 1998b). This group shows a similar degree of spatial synchrony in this and other studies (Caffey 1985, Judge et al. 1988). Similarly, lack of synchrony in lowshore algal species in this study has also been found elsewhere (Chapman \& Underwood 1998, Underwood \& Chapman 1998, Menconi et al. 1999). Low-shore algae may be more susceptible to direct effects of local factors, such as anthropogenic disturbance (BenedettiCecchi et al. 2001) or grazing (Benedetti-Cecchi et al. 2000). Where these effects are consistent over large scales, large-scale changes may result (BenedettiCecchi et al. 2001). More often it seems that processes affecting low shore algae are idiosyncratic to particular conditions prevailing at each site.

The spatial extent of population synchrony has obvious implications for monitoring strategies. Such is the degree of synchrony in Semibalanus balanoides, for example, that changes at a single site adequately reflect changes over the whole of SW England (Southward et al. 1995). More sites will be needed to estimate large-scale changes in species with weaker synchrony among sites.

Long-term study of rocky shore communities has shown that some of the dominant species are good indicators of ecosystem responses to climatic change (Southward et al. 1995). This study indicates that species other than barnacles common on rocky shores show relatively low correlation among time series, and therefore may be less sensitive indicators. Climate change should affect all sites similarly. However, most of the sites in this study were over a very limited spatial scale $(0$ to $30 \mathrm{~km})$ in a semi-enclosed area that may be more prone to local effects, such as the effects of the oil terminal on dogwhelks, rather than climatic effects. This contrasts with the choice of open coastal sites for monitoring programmes intended to detect climatic influences (such as COST 47: Lewis 1984). The complexity of the local coastline may also mitigate broadscale synchrony driven by climate.

Acknowledgements. We would like to thank all those who have taken part in the Sullom Voe rocky shore surveys since its inception, for its original design and for providing the data. The study was made possible by financial support for the monitoring programme by the Sullom Voe Association, and the Shetland Oil Terminal Environmental Advisory Group. We would also like to thank CORDAH Limited for providing facilities. The work forms part of the Northern Seas Programme of the Scottish Association for Marine Science at Dunstaffnage Marine Laboratory supported by the Natural Environment Research Council. The work also contributes to the MARCLIM 'Marine Biodiversity and Climate Change' consortium project.

\section{LITERATURE CITED}

Ballantine WJ (1961) A biologically-defined exposure scale for the comparative description of rocky shores. Field Stud $1: 1-19$

Barnes H (1956) Balanus balanoides (L.) in the Firth of Clyde: the development and annual variation of the larval population and causative factors. J Anim Ecol 25:72-84

Benedetti-Cecchi L, Bulleri F, Cinelli F (2000) The interplay of physical and biological factors in maintaining mid-shore and low-shore assemblages on rocky coasts in the northwest Mediterranean. Oecologia 123:406-417

Benedetti-Cecchi L, Pannacciulli F, Bulleri F, Moschella PS, Airoldi L, Relini G, Cinelli F (2001) Predicting the consequences of anthropogenic disturbance: large-scale effects of loss of canopy algae on rocky shores. Mar Ecol Prog Ser 214:137-150

Bjørnstad ON, Bolker B (2000) Canonical functions for dispersal-induced synchrony. Proc R Soc Lond B 267:1787-1794

Burrows MT, Hawkins SJ (1998) Modelling patch dynamics on rocky shores using deterministic cellular automata. Mar Ecol Prog Ser 167:1-13

Caffey HM (1985) Spatial and temporal variation in settlement and recruitment of an intertidal barnacle. Ecol Monogr 55:313-332

Chapman MG, Underwood AJ (1998) Inconsistency and variation in the development of rocky intertidal assemblages. J Exp Mar Biol Ecol 224:265-289

Crisp DJ, Southward AJ (1958) The distribution of intertidal organisms along the coasts of the English Channel. J Mar Biol Assoc UK 37:157-208

Davies IM, Bailey SK (1991) The impact of tributyltin from large vessels on dogwhelk (Nucella lapillus) populations around Scottish oil ports. Mar Environ Res 32:201-211

Day AJ (1990) Microgeographic variation in allozyme frequencies in relation to the degree of exposure to wave action in the dogwhelk Nucella lapillus (L.) (Prosobranchia, Muricacea). Biol J Linn Soc 40:245-261

Dayton PK, Tegner MJ, Edwards PB, Riser KL (1999) Temporal and spatial scales of kelp demography: the role of oceanographic climate. Ecol Monogr 69:219-250

Dye AH (1998a) Dynamics of rocky intertidal communities: analyses of long time series from South African shores. Estuar Coast Mar Sci 46:287-305

Dye AH (1998b) Community-level analyses of long-term changes in rocky littoral fauna from South Africa. Mar Ecol Prog Ser 164:47-57

Efron B, Gong G (1983) A leisurely look at the bootstrap, the jackknife and cross-validation. Am Stat 37:36-48

Fox CJ, Planque BP, Darby CD (2000) Synchrony in the recruitment time-series of plaice (Pleuronectes platessa L.) around the United Kingdom and the influence of sea temperature. J Sea Res 44:159-168

Gaines SD, Brown S, Roughgarden J (1985) Spatial variation in larval concentration as a cause of spatial variation in the barnacle, Balanus glandula. Oecologia 67:267-272 
Harding MJC, Rodger GK, Davies IM, Moore JJ (1997) Partial recovery of the dogwhelk (Nucella lapillus) in Sullom Voe, Shetland from tributyltin contamination. Mar Environ Res 44:285-304

Hawkins SJ, Hartnoll RG (1982) Settlement patterns of Semibalanus balanoides (L.) in the Isle of Man. J Exp Mar Biol Ecol 62:271-283

Hawkins SJ, Southward AJ (1992) The Torrey Canyon oil spill: recovery of rocky shore communities. In: Thayer GW (ed) Restoring the nation's marine environment. Maryland Sea Grant College, College Park, p 584-631

Heino M, Kaitala V, Ranta E, Lindström J (1997) Synchronous dynamics and rates of extinction in spatially structured populations. Proc R Soc Lond Ser B Biol Sci 264:481-486

Higgins K, Hastings A, Sarvela JN, Botsford LW (1997) Stochastic dynamics and deterministic skeletons: population behaviour of Dungeness crab. Science 276:1431-1435

Hiscock K (1981) The rocky shore ecology of Sullom Voe. Proc R Soc Edinb Sect B (Biol) 80:219-240

Johnson MP (2000) Temporally explicit habitat ecology and the coexistence of species. Proc R Soc Lond Ser B Biol Sci 267:1967-1972

Johnson MP, Burrows MT, Hawkins SJ (1998) Individual based simulations of the direct and indirect effects of limpets on a rocky shore Fucus mosaic. Mar Ecol Prog Ser 169:179-188

Judge ML, Quinn JF, Wolin CL (1988) Variability in recruitment of Balanus glandula (Darwin, 1854) along the central California coast. J Exp Mar Biol Ecol 119:235-251

Kendall MA, Bowman RS, Williamson P, Lewis JR (1982) Settlement patterns, density and stability in the barnacle Balanus balanoides. Neth J Sea Res 16:119-126

Kendall MA, Bowman RS, Williamson P, Lewis JR (1985) Annual variation in the recruitment of Semibalanus balanoides on the North Yorkshire coast. J Mar Biol Assoc UK 65:1009-1030

Kirby RR, Berry RJ, Powers DA (1997) Variation in mitochondrial DNA in a cline of allele frequencies and shell phenotype in the dog-whelk Nucella lapillus (L.). Biol J Linn Soc 62:299-312

Koenig WD (1999) Spatial autocorrelation of ecological phenomena. Trends Ecol Evol 14:22-26

Lewis JR (1984) Temporal and spatial changes in benthic communities: COST 47 approach. Mar Pollut Bull 15: 397-402

Lewis JR, Bowman RS, Kendall MA, Williamson P (1982) Some geographical components in population dynamics: possibilities and realities in some littoral species. Neth $\mathrm{J}$ Sea Res 16:18-28

Menconi M, Benedetti-Cecchi L, Cinelli F (1999) Spatial and temporal variability in the distribution of algae and invertebrates on rocky shores in the northwest Mediterranean. J Exp Mar Biol Ecol 233:1-23

Moore J, Taylor P, Hiscock K (1995) Rocky shores monitoring programme. In: Dunnett GM, McIntyre AD (eds) Monitoring at an oil terminal: the Shetland experience. Proc R Soc Edinb Sect B (Biol) 103B:181-200

Moran PAP (1953) The statistical analysis of the Canadian lynx cycle. II. Synchronization and meteorology. Aust J Zool 1:291-298

Paradis E, Baillie SR, Sutherland WJ, Gregory RD (2000) Spatial synchrony in populations of birds: effects of habitat, population trend, and spatial scale. Ecology 81:2112-2125

Pollard E (1991) Synchrony of population fluctuations: the dominant influence of widespread factors on local butterfly populations. Oikos 60:7-10

Editorial responsibility: Otto Kinne (Editor), Oldendorf/Luhe, Germany
Ranta E, Kaitala V, Lindström J, Linden H (1995) Synchrony in population dynamics. Proc R Soc Lond Ser B Biol Sci 262: 113-118

Ranta E, Kaitala V, Lindström J, Helle E (1997) The Moran effect and synchrony in population dynamics. Oikos 78 : $136-142$

Reed DC, Laur DR, Ebeling AW (1988) Variation in algal dispersal and recruitment: the importance of episodic events. Ecol Monogr 58:321-335

Roughgarden J, Gaines S, Possingham H (1988) Recruitment dynamics in complex life cycles. Science 241:1460-1466

Shanks AL (1983) Surface slicks associated with tidally forced internal waves may transport pelagic larvae of benthic invertebrates shoreward. Mar Ecol Prog Ser 13: 311-315

Sousa WP (1984) Intertidal mosaics: patch size, propagule availability and spatially variable patterns of succession. Ecology 65:1918-1935

Southward AJ (1967) Recent changes in abundance of intertidal barnacles in south-west England: a possible effect of climatic deterioration. J Mar Biol Assoc UK 47:81-95

Southward AJ (1980) The western English Channel-an inconstant ecosystem? Nature 285:361-366

Southward AJ (1991) Forty years of changes in species composition and population-density of barnacles on a rocky shore near Plymouth. J Mar Biol Assoc UK 71:495-513

Southward AJ, Crisp DJ (1954) Recent changes in the distribution of the intertidal barnacles Chthamalus stellatus Poli and Balanus balanoides L. in the British Isles. J Anim Ecol 23:163-177

Southward AJ, Crisp DJ (1956) Fluctuations in the distribution and abundance of intertidal barnacles. J Mar Biol Assoc UK 35:211-229

Southward AJ, Southward EC (1978) Recolonization of rocky shores in Cornwall after use of toxic dispersants to clean up the Torrey Canyon spill. J Fish Res Board Can 35: 682-706

Southward AJ, Hawkins SJ, Burrows MT (1995) Seventy years' observations of changes in distribution and abundance of zooplankton and intertidal organisms in the western English Channel in relation to rising sea temperature. J Therm Biol 20:127-155

Svane I (1984) Observations on the long-term population dynamics of the perennial ascidian, Ascidia mentula O.F. Müller, on the Swedish west coast. Biol Bull (Woods Hole) 167:630-646

Swanson BJ, Johnson DR (1999) Distinguishing causes of intraspecific synchrony in population dynamics. Oikos 86:265-274

Underwood AJ, Chapman MG (1998) Variation in algal assemblages on wave-exposed rocky shores in New South Wales. Mar Freshw Res 49:241-254

Underwood AJ, Fairweather PG (1989) Supply-side ecology and benthic marine assemblages. Trends Ecol Evol 4: $16-20$

Underwood AJ, Peterson CH (1988) Towards an ecological framework for understanding pollution. Mar Ecol Prog Ser 46:227-234

Underwood AJ, Denley EJ, Moran MJ (1983) Experimental analyses of the structure of rocky intertidal communities in New South Wales. Oecologia (Berl) 56:202-219

Watson A, Moss R, Rothery P (2000) Weather and synchrony in 10-year population cycles of rock ptarmigan and red grouse in Scotland. Ecology 81:2126-2136

Ziljstra JJ, Witte JIJ (1985) On the recruitment of 0-group plaice in the North Sea. Neth J Zool 35:360-376

Submitted: August 27, 2001; Accepted: April 15, 2002

Proofs received from author(s): August 23, 2002 